Copyright (C) 2012 IEEE. Personal use of this material is permitted. Permission from IEEE must be obtained for all other uses, in any current or future media, including reprinting/republishing this material for advertising or promotional purposes, creating new collective works, for resale or redistribution to servers or lists, or reuse of any copyrighted component of this work in other works. 


\title{
Power System Transient Stability Enhancement using Direct Drive Wind Generators
}

\author{
Hasmina Tari Mokui, Student Member, IEEE, Mohammad A.S. Masoum, Senior Member, IEEE, \\ Mansour Mohseni, Member, IEEE, and Moayed Moghbel, Student Member, IEEE
}

\begin{abstract}
Recent grid codes requires the wind farms not only to ride through the fault disturbances but also support the stability of nearby grid during severe network disturbances. This paper presents the impact of direct drive wind generators to the improvement of fault ride through (FRT) capability of fixed speed wind turbine. Three operational strategies have been investigated, i.e. without reactive power support, considering reactive power support complying with the Danish grid codes (with and without considering overloading of the converter currents). The proposed control strategies enable the direct drive wind generators to inject the required reactive power in order to help stabilizing the nearby fixed speed wind generators during faults. Simulation studies are carried out by using MATLAB/SIMULINK.
\end{abstract}

Index Terms-Fixed speed wind generators, fault ride through, direct drive wind generators, reactive power support, voltage stability.

\section{INTRODUCTION}

G LOBAL cumulative installed wind power generation capacity has increased tremendously in the last two decades, i.e. from 6,100 MW in 1996 to $197,039 \mathrm{MW}$ in 2010 [1]. As harnessing wind power is increasing, Transmission System Operators (TSOs) set the grid codes that require wind farms to ride through the fault and support the stability of the nearby grid during severe network faults.

Implementation of grid codes worldwide has been reported in various works and mostly suggested the utilization of variable speed generators such as DFIGs [2, 3] and full converter based wind generation systems [4-7]. However, fixed speed generator are still contributing about $20 \%$ to $30 \%$ of global wind capacity [8], which mostly were installed in the 1980 s to 1990s. During that period, technology in power electronic converter has not advanced as nowadays, therefore such type of wind generators has limitation in handling network faults.

Fixed speed wind generator consisting of squirel cage induction machine is well known for its simple installation, economical cost, as well as brushless and rugged construction. Since this technology is not equipped with any power electronic converter, transient disturbances and fault

H.T. Mokui, M.A.S. Masoum, M. Mohseni and M. Moghbel are with the Department of Electrical and Computer Engineering, Curtin University, Perth, WA 6845 Australia (e-mail: h.mokui@postgrad.curtin.edu.au, m.masoum@curtin.edu.au, mansour.mohseni@curtin.edu.au and moayed. moghbel@postgrad.curtin.edu.au). conditions do not cause major threat to the electrical parts of the generator. However, when a short circuit fault occurs in the power system, the electromagnetic torque of the machine reduces proportional to the square of the remnant voltages causing the rotor to accelerate beyond its safety limits. Also, as the fault occurs, the induction machine absorbs large reactive power in order to recover the air gap flux [9]. Otherwise, large difference between electromagnetic and mechanical torques can lead to the instability of the machine. If reactive power cannot be fulfilled, then machine should be disconnected from power system because it can also exacerbate the voltage stability by absorbing reactive power from the network. Recent grid codes prevent the disconnection of the wind farms as it can lead to the cascading failures in the system.

Capability of the fixed speed wind turbine to ride through the faults can be improved by applying FACTS devices, fast pitching of the turbine blades during the fault period, using dynamic breaking resistors, or implementing superconducting magnetic energy storage (SMES) [10-16]. Among aforementioned solutions, SMES has been proved to be the most effective technology to improve the FRT capability of fixed speed wind generators but installation of SMES is not cost effective.

Direct drive wind turbine utilizing power electronic converter has the ability to not only withstand during the fault but also provide reactive power support to the grid. It has been demonstrated in $[6,17]$ that direct drive wind turbine can improve transient and voltage stability of its adjacent grid. In [9], it is also shown that the capability of fixed speed wind generators to ride through the fault can be improved by installing direct drive wind turbine in parallel and series. The control strategies are designed considering the grid codes set by the Federal Energy Regulatory Commission (FERC) but the effect of overloading the converter current is not shown.

The goal of this paper is to present the impacts of installing direct drive wind turbine in improving transient stability of the power system. Particularly in providing reactive power support during network disturbances, such that it can improve the fault ride through capability of fixed speed wind turbine. Danish grid codes will be taken into account for designing the control strategies.

\section{Simulation Set-UP AND Modeling}

The simulation analysis is conducted using MATLAB/SIMULINK. 


\section{A. Test System}

Fig. 1 shows the schematic of the simulated system, with parameters of the machines given in the Appendix. In this system, $5 \times 2 \mathrm{MW}$ direct drive wind generators are connected to the local $25 \mathrm{kV}$ distribution substation through $0.575 / 25 \mathrm{kV}$ step-up transformers and a $1 \mathrm{~km}$ underground cable. At the same substation (B25), the $2 \times 1.5 \mathrm{MW}$ fixed speed wind generators are also connected via $0.575 / 25 \mathrm{kV}$ transformers and $1 \mathrm{~km}$ underground cable. The aforementioned generators are connected to the local capacitor banks, installed at its terminals such that the induction machine operates close to unity power factor under steady state condition. The substation B25 is connected to the main grid through $25 \mathrm{~km}$ overhead transmission line and a $25 / 120 \mathrm{kV}$ transformer. The main grid is represented by its Thevenin equivalent circuit; i.e., an ideal voltage source $\mathbf{V}_{s}$ in series with impedance $\mathbf{Z}_{\text {s. }}$. Various symmetrical and asymmetrical fault conditions in the network are emulated by varying the amplitude of one, two, or three phases of the $\mathbf{V}_{\text {s }}$ source with time.

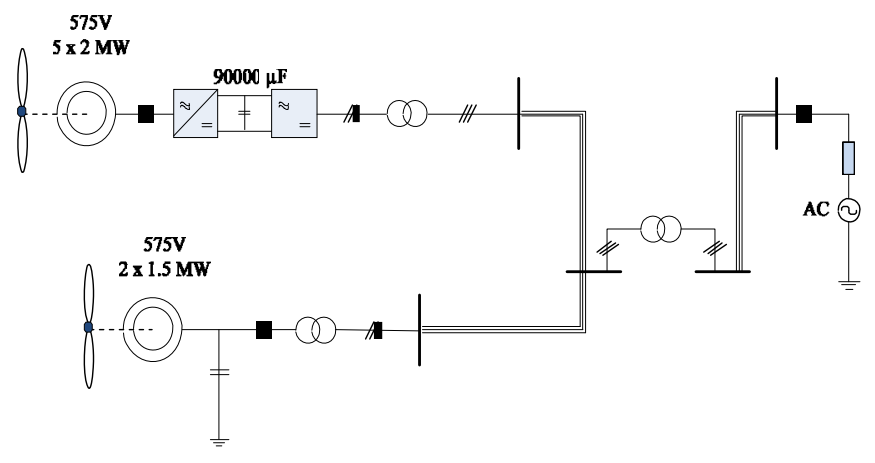

Fig. 1. Schematic diagram of the simulated system

\section{B. Wind Turbine Modelling}

Fig. 2 shows the drive train system for stability analysis considering severe network disturbances. In [4], it is stated that for such study, the drive train system must be approximated by at least a two-mass model.

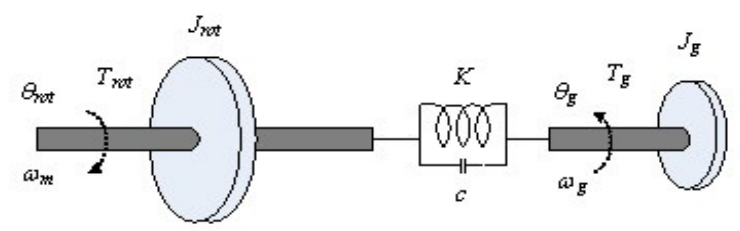

Fig. 2. Drive train model

In the wind turbine integration studies, it is common to define the wind turbine mechanical power output as [7]

$$
P_{w}=\frac{1}{2} \pi \rho R^{2} v_{w}^{3} C_{p}(\lambda, \beta)
$$

where $P_{w}$ is the extracted wind power ; $\rho$ is the air density; $R$ is the radius of rotor ; $v_{w}$ is the wind speed; $\lambda$ is the tip speed ratio; $\beta$ is the blade pitch angle; and $C_{p}$ is the efficiency coefficient of the turbine which is a function of $\lambda$ and $\beta$. The tip speed ratio $\lambda$ is expressed as [7]:

$$
\lambda=\frac{\omega_{r} R}{v_{w}}
$$

where $\omega_{r}$ is the turbine rotational speed.

In the fully rated converter wind generation, the speed control does not only depend on the generator, but also on the wind turbine drive power characteristics [18], so integrating the two parts is important for dynamic study of the machine. Fig. 3 presents the pitch control system using a PI controller with anti-wind-up [4, 19]. Its function is to control the generator speed by controlling the pitch angle of the blade and its rate-of-change such that over speeding of the wind turbine can be avoided.

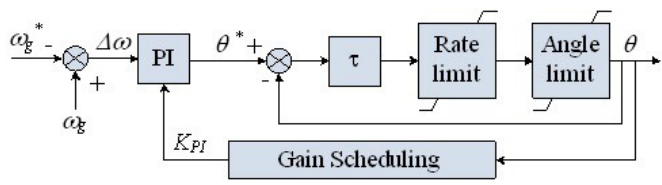

Fig. 3. Pitch control model

\section{Direct Drive Wind Turbine}

The general configuration of simulated direct drive wind turbine generation system utilizes salient pole rotor structure generator with the gear box which is decoupled from the grid through the grid side converter. The machine is connected to a diode rectifier while the grid side converter utilizes a selfcommutate PWM inverter. The control system for pitch control is based on [19].

The machine side converter in this study is composed of diode rectifier, DC-DC boost converter and DC link capacitor $[20,21]$. The rectifier converts the $\mathrm{AC}$ output of the generator to DC voltage while the DC-DC boost converter controls the rectifier output current, $I_{D C}$, and the electric power, $P_{\text {grid }}$. In the grid side, a PWM inverter adopting the cascaded control scheme is applied (Fig. 4). This inverter is responsible to maintain the DC-link voltage, $\mathrm{V}_{D C}$, at constant value and control the flow of reactive power, $Q_{\text {grid }}$, to the grid $[4,20$, 21]. The var/voltage control for this study is built based on [19]. Current regulator at the grid side converter applies the vector based hysteresis current control (VBHCC) [22, 23]. Testing performance of $\mathrm{VBHCC}$ on direct drive wind generators has been presented in [24].

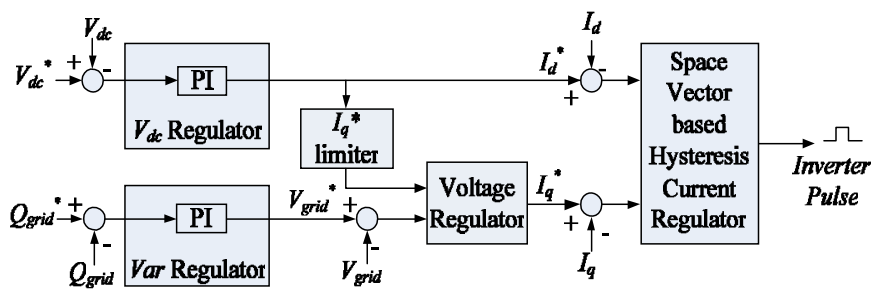

Fig 4. Control block diagram of the simulated grid side converter

Theoretically, full converter based wind turbine can ride through any grid faults (symmetrical or unsymmetrical) as the generator is fully decoupled from the grid through the grid side inverter. The reactive power exchange merely depends on the characteristic of the grid side converter and not on the generator properties $[4,25]$. Therefore, capability of the 
machine to inject reactive power is utilized at the grid side converter.

\section{Maximum Current Capacity of Converters}

Danish Grid Code requires WPPs to be capable of continuously operating at their rated active power with the power factor in the range of 0.95 capacitive to 0.95 inductive. The upper and lower limits of the supply voltage amplitude for continuous operation of the generating units are specified as $\left|V_{\text {s, } \max }\right|=1.1$ p.u. and $\left|V_{s, m i n}\right|=0.9$ p.u. [26]. These specifications must be taken into account to calculate the maximum current-carrying capacity of the network side converter $\left(I_{\max }\right)$. An appropriate design of converter current capacity should make sure that the active and reactive power requirements of the FRC-based wind generator can be attained under the most onerous operating conditions without violating the thermal limits of the semiconductor switches (e.g., IGBTs) used in the VSCs.

In order to obtain the analytical expression of $I_{\max }$, the active and reactive powers of FRC-based wind generators are needed. If the scaling factors of Clarke's Transformation are omitted, the active and reactive powers in the synchronous frame are defined by

$$
\begin{aligned}
& P=\left|V_{s}\right| I_{r d} \\
& Q=\left|V_{s}\right| I_{r q}
\end{aligned}
$$

where $|\mathrm{Vs}|$ is the supply voltage amplitude, and $I_{r d}$ and $I_{r q}$ are the quadrature components of the network side converter (NSC) in the grid voltage-oriented frame [27]. Based on (3), the amplitude of current in the NSC can be obtained as

$$
|I|=\sqrt{I_{d}^{2}+I_{q}^{2}}=\sqrt{\left(\begin{array}{l}
P \\
\mid \\
V_{s} \mid
\end{array}\right)^{2}+\left(\mid \frac{Q}{\left|V_{s}\right|}\right)^{2}}
$$

Based on (4), the maximum current in the NSC is required when both $\mathrm{P}$ and $\mathrm{Q}$ are at their rated values, and the supply voltage amplitude is at its minimum values, i.e., $\mathrm{P}=1.0$ p.u., $\mathrm{Q}=0.328$ p.u. and $|\mathrm{Vs}|=0.9$ p.u. Substituting these values in (4), the $I_{\max }$ is obtained equal to 1.17 p.u. This means that the rated current of the NSC must be $17 \%$ larger than its rated active power or Id, $\max =0.85|\operatorname{Imax}|$. The extra current capacity in the NSC is needed to provide the rated capacitive/inductive reactive power of 0.328 p.u. in case needed by the network.

\section{E. Modified Reactive Power Support}

Three design strategies are considered, as follows:

1. Design 1: the conventional wind turbine control design (with no reactive power support);

2. Design 2: modified control design to comply with Danish reactive power support requirements. This means that reactive component of the grid side converter current vector increases by $2 \%$ for each $1 \%$ reduction in the PCC voltage for voltage drops below $0.9 \mathrm{pu}$.

3. Design 3: modified control design to comply with Danish reactive power support requirements along with temporary overloading of the grid side converter. In this case, the maximum converter current is allowed to be $141 \%$ than its default, i.e. $110 \%$.

\section{Simulation Results}

Three types of designs have been considered in this study in order to see the ability of the direct drive wind turbine to allow reactive power injection during grid faults. For this purpose, the system will be subjected to a symmetrical three phase fault at the infinite bus and unsymmetrical phase to phase faults at the terminal (Bus 575) of the direct drive wind generators with durations of $500 \mathrm{~ms}$ and $1 \mathrm{~s}$, respectively.

Response of the system under symmetrical fault is presented in Fig. 5 while Fig. 6 presents simulation results for phase-to-phase fault. As can be seen from Figs. 5 (a-c), with Design 1, direct drive wind turbine is not equipped with reactive power supports. The system is aimed to work at power factor of 0.95 as requested by Danish grid Codes. Under normal condition, the reactive current component, $I_{q}$, at direct drive wind turbine is set equal to 0.25 p.u. When the fault occurs and the grid voltage becomes less than 0.9 p.u. then $I_{q}$ is set to drop to 0 p.u. For both fixed and direct drive wind generators, $50 \%$ voltage sag at the grid will cause voltage drops at its terminal, as a result, the power delivered to the grid, $P_{\text {grid }}$, reduces from its steady state. For fixed speed wind turbines, voltage drop at its terminal leads to excessive consumption of reactive power. Therefore, as the fault is cleared, it cannot recover to its steady state while the direct drive wind generators are able to ride through the fault.

Response of wind generators with Design 2 are presented in Figs. 5 (d-f). Under normal condition, reactive power is maintained at 0 p.u. When the fault occurs, the wind generator must help the supply voltage restoration by injecting $2 \%$ reactive current component for each $1 \%$ drop in the supply voltage amplitude. Accordingly, the $I_{q}$ component starts to increase linearly from 0.2 p.u. with the slope of 2 .

In Design 3, the grid side converter output current is allowed to temporarily increase to 1.41 times of its nominal capacity during the fault period (see Figs. 5 (g-i)). Note that this is not a major threat for the semiconductor switches because modern power converters are designed to withstand short-term overloading. Semikron SKiiP ${ }^{\circledR}$ Intelligent Power Modules, for example, can tolerate $150 \%$ overloading for $20 \mathrm{~s}$ [28]. In Danish Grid Code, the maximum fault duration for the rated reactive power injection ( $|\mathrm{Vs}|=0.5$ p.u.) is defined equal to $1 \mathrm{~s}$; therefore, the grid side converter can be safely overloaded by $41 \%$ during the requested fault period.

As for Designs 2 and 3, FRT capability of fixed speed wind generators can be improved due to reactive power injected by the direct drive wind generators during faults. During the fault, the rotor of induction generators accelerates slightly but then it decelerates to its nominal value as the fault is cleared. In the direct drive wind generators, the grid side converter keeps enabling the voltage regulator to control the reactive power injection to the grid. Thus, the grid voltage manages to quickly recover to 1.0 p.u. The generator side converter is also activated right after the fault clearance so that the wind farms can continue supplying electric power at the rated value to the grid. During the fault period, the overshoot in the DC link voltage, $V_{D C}$, depends on the superfluous power that is 
(a)

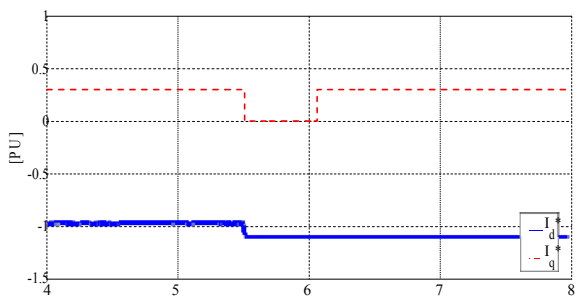

(b)

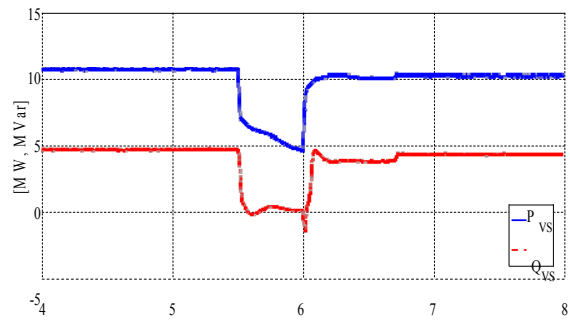

(c)

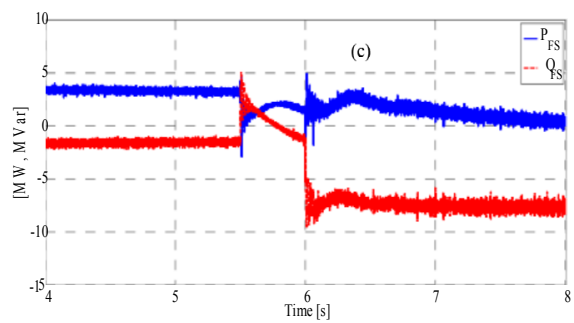

(d)

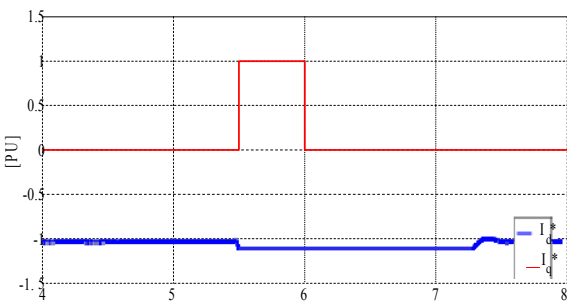

(e)

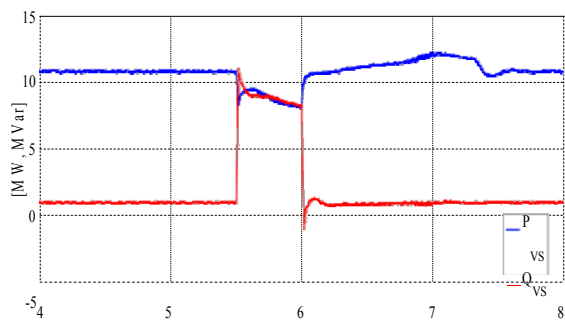

(f)

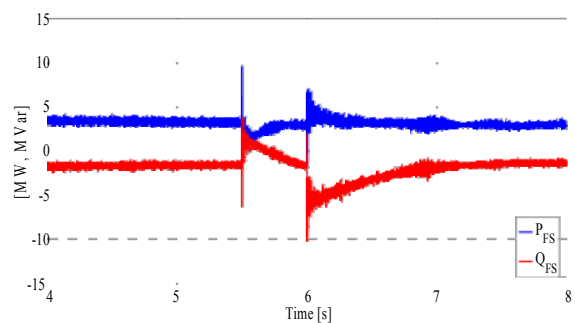

(g)

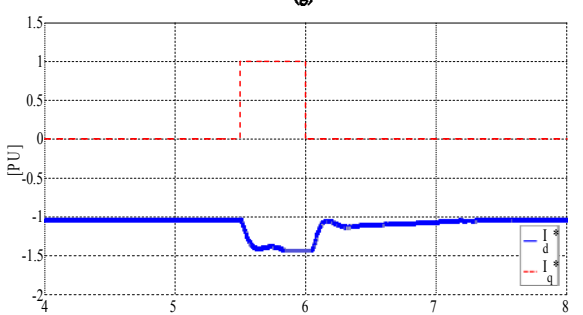

(h)

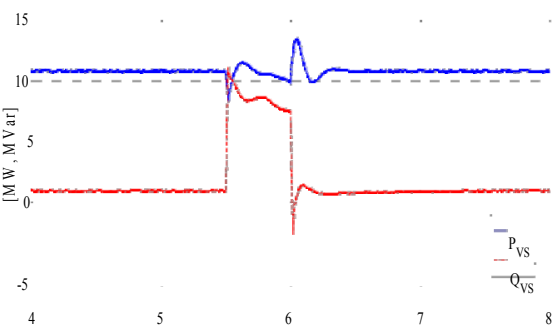

(i)

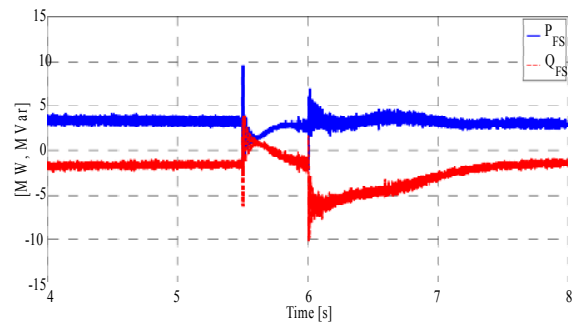

Fig. 5. Quadrature components of the grid side converter currents, $\mathrm{P}-\mathrm{Q}$ response for fixed speed wind generators and direct drive wind generators under $50 \%$ voltage sag, sustained for $500 \mathrm{~ms}$ : (a)-(c) Design 1; (d)-(f) Design 2; (g)-(i) Design 3

(a)

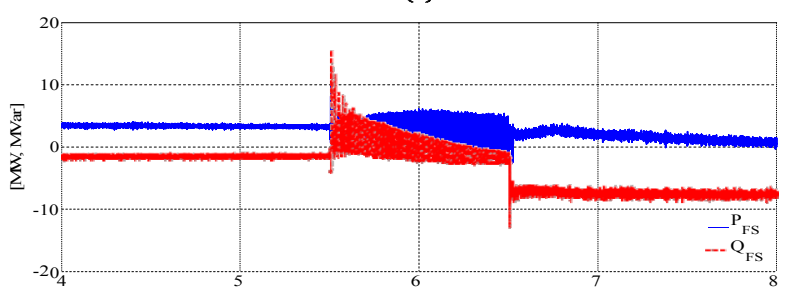

(c)

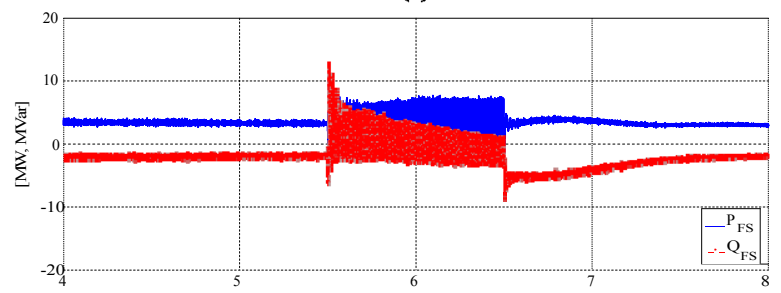

(e)

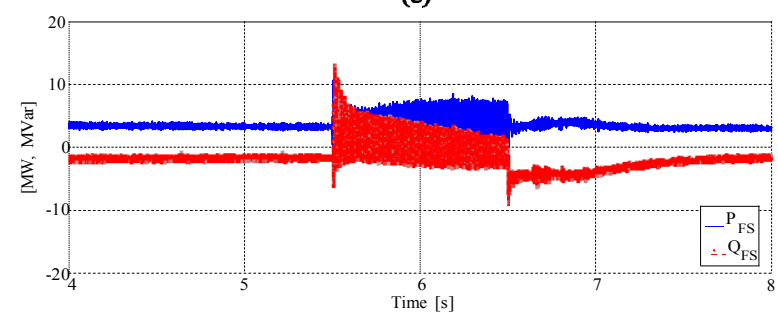

(b)

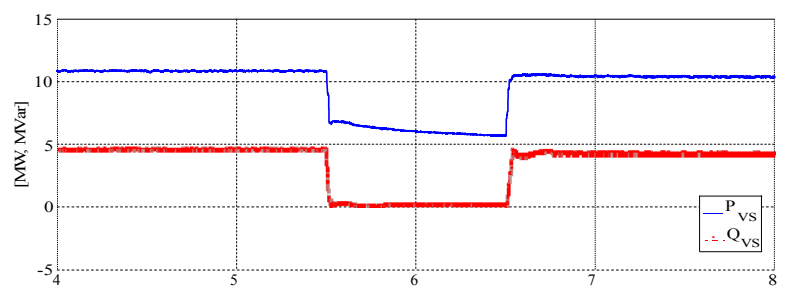

(d)
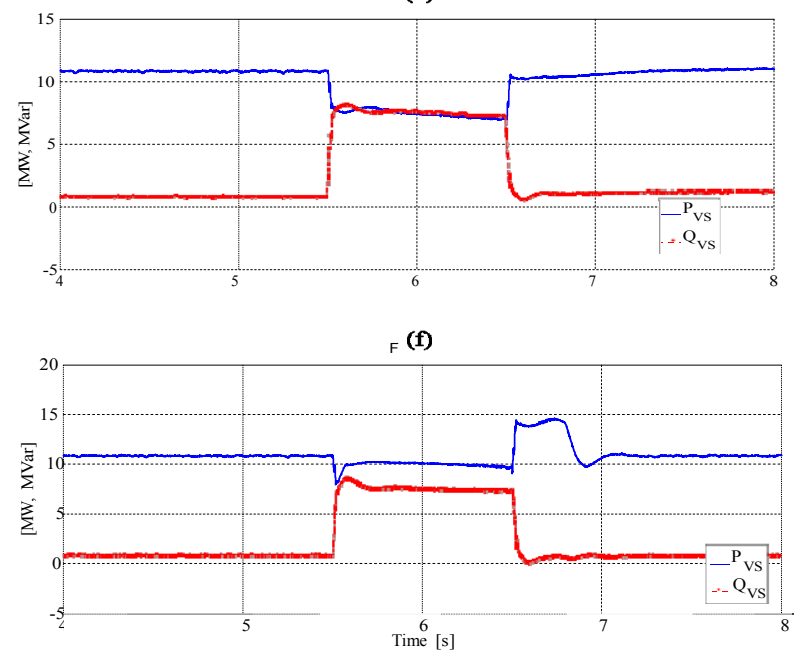

Fig. 6. P-Q response for direct drive wind generators and fixed speed wind generators under a phase to phase fault, sustained for 1s: (a)-(b) Design 1; (d) Design 2; (e)-(f) Design 3 
injected to the capacitor from the generator. Similar features are also found when system is subjected to the unsymmetrical sag at Bus 575 of direct drive wind turbine (see Fig. 6). Design 2, Fig. 6(c-d), and Design 3, Fig. 6 (e-f) allow the direct drive wind generators to ride through the fault while injecting reactive power to its nearby grid even though longer fault duration has been applied.

Fig. 7 shows the profile of DC link voltage of the direct drive wind generators for applied designs under unsymmetrical fault. It is clear that the highest overshoots in the DC link voltage is for Design 1 due to large mismatch between power produced by the generator and the power that is able to delivered to the grid during fault period.

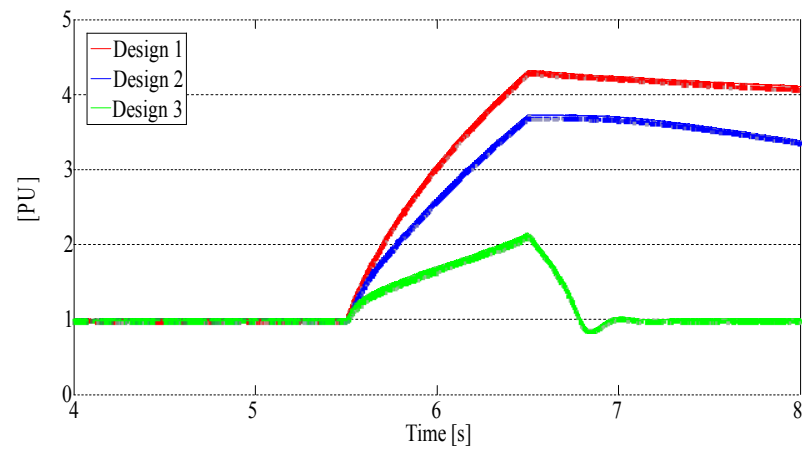

Fig 7. DC link voltage for different designs

\section{CONCLUSIONS}

Impacts of three different designs of direct drive wind generators in providing reactive power support to its nearby grid have been investigated. Apart from modified reactive power control, the grid side converter also applies SVBHCC which has simple control structure, very fast transient response and intrinsic robustness to the machine parameters. Simulation studies confirm that the voltage profile of fixed speed wind generators can be improved with $2 \%$ reactive power support from variable speed wind generators. Moreover, direct drive wind generators are able to ride through the fault while injecting the reactive power to the grid during the fault periods. In addition, the converter has the lowest DC link voltage as the capacity of converter current is increased from its nominal value.

\section{APPENDIX}

Table 1 presents the simulation parameters for direct drive wind generators while Table 2 depicts machine parameters of fixed speed wind generators.
TABLE I

SIMULATION PARAMETERS FOR DIRECT DRIVE WIND TURBINES

\begin{tabular}{|l|l|}
\hline \multicolumn{2}{|c|}{ Generator Parameters } \\
\hline Rated Power & $2 \mathrm{MW}$ \\
\hline Stator voltage/Frequency & $575 \mathrm{~V} / 60 \mathrm{~Hz}$ \\
\hline$R_{s}$ & $0.006 \mathrm{p} \cdot \mathrm{u}$. \\
\hline$X_{d} / X_{q} / X_{l}$ & $1.305 \mathrm{p} . \mathrm{u} / 0.474 \mathrm{p} . \mathrm{u} /$ \\
& $0.18 \mathrm{p} . \mathrm{u}$ \\
\hline$H$ & $2.32 \mathrm{Sec}$ \\
\hline$V_{d c}$ & $1100 \mathrm{Volt}$ \\
\hline Grid side coupling inductor, $L / R$ & $0.15 \mathrm{p} . u / 0.03 \mathrm{p} . u$ \\
\hline Boost converter inductance, $L / R$ & $0.0012 \mathrm{H} / 0.005 \Omega$ \\
\hline Wind Turbine parameters & $2 \mathrm{MW}$ \\
\hline Nominal mechanical output power & $11 \mathrm{~m} / \mathrm{s}$ \\
\hline Base wind speed & $1.1 \mathrm{p} . u$. \\
\hline Maximum power at base wind speed & $0^{\circ}$ \\
\hline Initial pitch angle & $4.32 \mathrm{~s}$ \\
\hline Inertia Constant &
\end{tabular}

TABLE II

SIMULATION PARAMETERS FOR FIXED SPEED WIND GENERATORS

\begin{tabular}{|l|l|}
\hline \multicolumn{2}{|c|}{ Generator Parameters } \\
\hline Rated power & $1.5 \mathrm{MW}$ \\
\hline Rated Voltage/Rated frequency & $575 \mathrm{~V}, 50 \mathrm{~Hz}$ \\
\hline Stator/Rotor resistances & $0.005,0.1248 \mathrm{p} . u$. \\
\hline Leakage / Mutual inductances & $0.4,6.77 \mathrm{p} . u$. \\
\hline Local capacitor bank & $0.4 \mathrm{MVar}$ \\
\hline Wind Turbine parameters \\
\hline Nominal mechanical output power & $1.5 \mathrm{MW}$ \\
\hline Base wind speed & $9 \mathrm{~m} / \mathrm{s}$ \\
\hline Maximum power at base wind speed & $1.0 \mathrm{p} . u$. \\
\hline Turbine inertia constant & $5.04 \mathrm{~s}$ \\
\hline
\end{tabular}

\section{REFERENCES}

[1] Global Wind Energy Council, "Global Wind Report: Annual Market Update 2010," March 2011. Available at http://www.gwec.net/fileadmin/documents/Publications/Global_Wind 2007_report/GWEC\%20Global\%20Wind\%20Report\%202010\%20low $\% 20$ res.pdf.

[2] D. Chwa and K. B. Lee, "Variable Structure Control of the Active and Reactive Powers for a DFIG in Wind Turbines," IEEE Trans Industry Applications, vol. 46, pp. 2545-2555, Nov./Dec 2010.

[3] M. Mohseni, S. Islam, and M. Masoum, "Impacts of Symmetrical and Asymmetrical Voltage Sags on DFIG-Based Wind Turbines Considering Phase-Angle Jump, Voltage Recovery, and Sag Parameters," IEEE Trans. Power Electron., vol. 26, pp. 1587 - 1598, May 2011.

[4] A. D. Hansen and G. Michalke, "Multi-pole permanent magnet synchronous generator wind turbines' grid support capability in uninterrupted operation during grid faults," IET Renewable Power Generation, vol. 3, pp. 333-348, Sept. 2009.

[5] G. Ramtharan, A. Arulampalam, J.B. Ekanayake, F.M. Hughes and N. Jenkins, "Fault ride through of fully rated converter wind turbines with $\mathrm{AC}$ and DC transmission," IET Renewable Power Generation, vol. 3, pp. 426-438, Dec. 2009.

[6] N. R. Ullah, T. Thiringer and D. Karlsson, "Voltage and Transient Stability Support by Wind Farms Complying With the E.ON Netz Grid Code," IEEE Trans. Power Systems, vol. 22, pp. 1647-1656, Nov. 2007.

[7] J. F. Conroy and R. Watson, "Low-voltage ride-through of a full converter wind turbine with permanent magnet generator," IET Renewable Power Generation, vol. 1, pp. 182-189, Sept. 2007.

[8] IEA, 2009 IEA wind annual report, May 2010. Available at http://www.ieawind.org $>$.

[9] S. M. Muyeen, R. Takahashi, T. Murata, and J. Tamura, "A Variable Speed Wind Turbine Control Strategy to Meet Wind Farm Grid Code 
Requirements," IEEE Trans. Power Systems, vol. 25, pp. 331-340, Feb. 2010.

[10] H. Gaztanaga, I. E. Otadui, D. Ocnasu, and S. Bacha, "Realtime analysis of the transient response improvement of fixedspeed wind farms by using a reduced-scale STATCOM prototype," IEEE Trans. Power Syst., vol. 22, no. 2, pp. 658-666, May 2007.

[11] M. Molinas, J. A. Suul, and T. Undeland, "Low voltage ride through of wind farms with cage generators: STATCOM versus SVC," IEEE Trans. Power Electron., vol. 23, no. 3, pp. 1104-1117, May 2008.

[12] H M. J. Hossain, H. R. Pota, V. A. Ugrinovskii, and R. A.Ramos, "Simultaneous STATCOM and pitch angle control for improved LVRT capability of fixed-speed wind turbines," IEEE Trans. Sustain.. Energy, vol. 1, no. 3, pp. 142-151, Oct. 2010

[13] Z. Chen, Y. Hu and F. Blaabjerg, "Stability improvement of induction generator-based wind turbine systems," IET Renew. Power Gener., vol. 1, no. 1, pp. 81-93, Mar. 2007.

[14] W. Freitas, A. Morelato, and W. Xu, "Improvement of induction generator stability using braking resistors," IEEE Trans. Power Syst., vol. 19, no. 2, pp. 1247-1249, May 2004.

[15] S. Nomura, Y. Ohata, T. Hagita, H. Tsutsui, S. Tsuji-Iio, and R. Shimada, "Wind farms linked by SMES systems," IEEE Trans. Appl. Supercond., vol. 15, no. 2, pp. 1951-1954, Jun. 2005.

[16] S. M. Muyeen, M. Hasan Ali, R. Takahashi, T. Murata, J.Tamura, Y. Tomaki, A. Sakahara, and E. Sasano, "Comparative study on transient stability analysis of wind turbine generator system using different drive train models," IET Renew. Power Gener., vol. 1, no. 2, pp. 131-141, Jun. 2007.

[17] N. R. Ullah and T. Thiringer, "Variable Speed Wind Turbines for Power System Stability Enhancement," IEEE Trans. Energy Conversion, vol. 22, pp. 52-60, Mar. 2007.

[18] S. Li, T.A. Haskew, E. Muljadi and C. Serrentino, "Characteristic Study of Vector-controlled Direct-driven Permanent Magnet Synchronous Generator in Wind Power Generation," Electric Power Components and Systems, vol. 37, pp. 1162 - 1179, 2009.

[19] N. W. Miller, W.W. Price and J.J. Sanchez-Gasca, "Dynamic Modeling of GE 1.5 and 3.6 Wind Turbine-Generators," GE-Power Systems Energy Consulting, Oct. 2003. Available at http://www.easthavenwindfarm.com/filing/high/modeling.pdf.

[20] K. Ohyama, S. Arinaga and Y. Yamashita, "Modeling and simulation of variable speed wind generator system using boost converter of permanent magnet synchronous generator," in European Conf. on Power Electronics and Applications, pp. 1-9, Sept. 2007.

[21] S. M. Muyeen, R. Takahashi, T. Murata and J. Tamura, "A new control method of energy capacitor system in DC-based wind farm," in Energy Conversion Congress and Exposition, pp. 1619-1625. Sept. 2009.

[22] K. Bong-Hwan, M. Byung-Duk, and Y. Jang-Hyoun, "An improved space-vector-based hysteresis current controller," IEEE Trans. Industrial Electronics, vol. 45, pp. 752-760, Oct. 1998

[23] K. Bong-Hwan, K. Tae-Woo, and Y. Jang-Hyoun, "A novel SVMbased hysteresis current controller," IEEE Trans. Power Electronics, vol. 13, pp. 297-307, Mar. 1998.

[24] H.T. Mokui, M. Mohseni, and M.A.S. Masoum, "Impelementation of Space Vector based Hysteresis Current Control for Full Converter Wind Generation System ," in Proc. IEEE PES Innovative Smart Grid Technology Asia 2011. accepted for publication.

[25] T. Ackermann, Wind Power in Power System. Wiley, NJ, 2005.

[26] Energinet, Technical regulation 3.2.5 for wind power plants with a power output greater than $11 \mathrm{~kW}$, Sep. 2010. Available at $<\mathrm{http}: / / \mathrm{www}$.energinet.dk $>$

[27] A. Mullane, G. Lightbody, and R. Yacamini, "Wind-turbine fault ride through enhancement," IEEE Trans. Power Syst., vol. 20, no. 4, pp.1929-1937, Nov. 2005.

[28] Semikron, SEMISTAK Wind/Solar, March 2010. Available at http://www.semikron.com/

\section{BIOGRAPHIES}

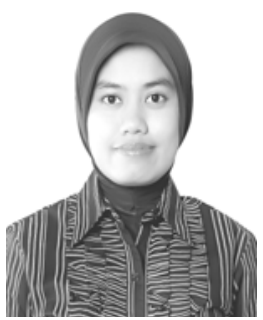

Hasmina Tari Mokui (S'11) received her B.Eng in 2003 from Hasanuddin University, Makassar, Indonesia and M.E. in 2007, from The University of Queensland, Brisbane, Australia. All in Electrical Engineering. She is currently working towards the $\mathrm{PhD}$ degree from Curtin University, Perth, Australia. Her current research interests include wind power generation, grid integration of renewable energy systems, power system stability and control as well as power electronics applications on power system.

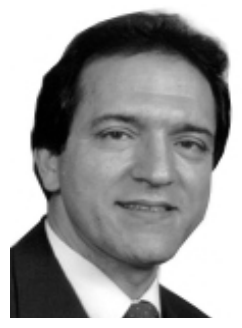

Mohammad A.S. Masoum (S'88-M'91-SM'05) received his B.S., M.S. and Ph.D. degrees in Electrical and Computer Engineering in 1983, 1985, and 1991, respectively, from the University of Colorado, Boulder, USA. His research interests include optimization, power quality and stability of power systems/electric machines and distributed generation. Dr. Masoum is the co-author of "Power Quality in Power Systems and Electrical Machines" (Elsevier, 2008) and "Power Conversion of Renewable Energy Systems" (Springer, 2011). Currently, he is an Associate Professor and the discipline leader for electrical power engineering at the Electrical and Computer Engineering Department, Curtin University, Perth, Australia and a senior member of IEEE.

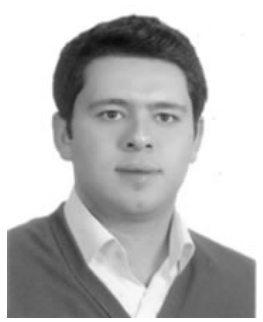

Mansour Mohseni (S'09, M'11) received the B.Sc. and M.Sc. degrees in electrical power engineering from Shahid Chamran University, Ahwaz, Iran, in 2004 and 2007, respectively, and the $\mathrm{PhD}$ degree in electrical and computer engineering from Curtin University, Perth, Australia, in 2011. He is currently an associate lecturer at the Department of Electrical and Computer Engineering, Curtin University, Perth, Australia.

$\mathrm{He}$ is the author or co-author of over 30 published technical papers in his area of expertise. His research interests include wind power generation, grid integration of renewable energy systems, and power electronics.

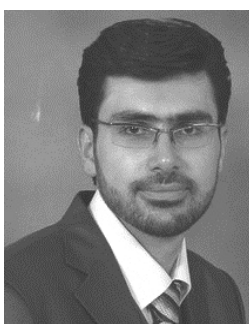

Moayed Moghbel (S'11) received his B.S. degree in Electrical Engineering from Khomeinishahr Azad University, Isfahan, Iran in 2003. He has four years experience in a petrochemical company as an electrical maintenance engineer and one year as a distribution project manager. His interests include power quality, protection and electrical machines. 